University of Nebraska - Lincoln

DigitalCommons@University of Nebraska - Lincoln

Sociology Department, Faculty Publications

Sociology, Department of

1985

\title{
Job Satisfaction and Women's Spheres of Work
}

Helen A. Moore

hmoore1@unl.edu

Follow this and additional works at: https://digitalcommons.unl.edu/sociologyfacpub

Part of the Sociology Commons

Moore, Helen A., "Job Satisfaction and Women's Spheres of Work" (1985). Sociology Department, Faculty Publications. 101.

https://digitalcommons.unl.edu/sociologyfacpub/101

This Article is brought to you for free and open access by the Sociology, Department of at DigitalCommons@University of Nebraska - Lincoln. It has been accepted for inclusion in Sociology Department, Faculty Publications by an authorized administrator of DigitalCommons@University of Nebraska - Lincoln. 
Published in Sex Roles 13: 11/12 (1985), pp. 663-678. Copyright @ 1985 Plenum Publishing Corporation. Used by permission.

A portion of this work was supported by a research grant from the Andrew Mellon Foundation, Henry A. Murray Research Center, Radcliffe College. Alan Booth and Lynn White provided valuable comments on an earlier draft of this paper.

\title{
Job Satisfaction and Women's Spheres of Work
}

\author{
Helen A. Moore \\ Department of Sociology, University of Nebraska-Lincoln
}

\begin{abstract}
Job satisfaction for women workers is traditionally researched from the job-gender model in which sex roles generate the research framework. Women employed in the labor market are viewed as responding primarily to the confines of sex roles, as opposed to the structural rewards and constraints of the labor market itself. We reexamined earlier studies that found no effect of the labor market on job satisfaction for women. Reanalysis of the 1972-1973 Quality of Employment national survey revealed significantly different levels of job satisfaction, which are in part structured by the characteristics of the labor market sectors in which women and men work. Women working in labor market sectors that are predominantly male or have a balanced proportion of male and female workers jobs have high job satisfaction. This job satisfaction is predicted almost exclusively by their perceptions of fewer income problems, flexibility of hours, and use of job skills. Factors related to maternity benefits and leaves are related only marginally to job satisfaction for women workers in either labor market sector. Women in predominantly female sectors of the labor market have similarly high job satisfaction scores, but these are related to a wider cluster of factors, including fewer perceived income problems, skills, and challenge factors, as well as the socioemotional rewards of their work. This pattern is most similar to males who work in predominantly male sectors. In contrast, males who work in predominantly female or gender-proportionate jobs have significantly lower job satisfaction scores, even after controlling for income issues and other benefits. Labor market sectors and the rewards available within them are important structural dimensions of job satisfaction for women and men employees.
\end{abstract}


To date, studies of women's work have focused on the amount of female labor force participation and on comparisons of men's and women's income, motivation, and job satisfaction. This research indicates that although women receive fewer economic rewards than men for similar types of work, women's self-esteem, job satisfaction, and motivation to work are as high or even higher than men's (Walshok \& Walshok, 1978). Why do women who obtain fewer rewards for their work have positive attitudes toward their jobs? Or are we asking the questions about women and their paid labor in a way that clouds the outcome?

To answer these questions, researchers have contrasted job satisfaction for men and women in the general labor force. Several studies suggest that, overall, women seek different rewards from work than do men, which may account for differences in job satisfaction ( $\mathrm{O}^{\prime}$ Leary, 1981). "Men seem to value economic rewards, management of others, recognition, independence and prestige more" (Gold, 1971). In contrast, support from co-workers, job content, and socioemotional factors are most often cited as the important determinants of job satisfaction for women (Andrisani, 1978).

The notion that the nature of rewards sought determines job satisfaction differences between men and women has focused attention on the social roles for women and men that affect their jobs. The research preoccupation with sex-role socialization has reinforced a job-gender model in the sociology of work which omits those structural factors that channel or reinforce labor market discrimination (Feldberg \& Glenn, 1982). Andrisani (1978) investigated the effects of women's traditional household responsibilities on satisfaction perceived from work outside the home. His findings indicate that women with greater home and child care demands have lower job satisfaction. O'Leary (1981) points to home pressures as the most important contributors to role conflict and low satisfaction for employed married women since these activities generate considerable conflicts in time and self-esteem. Employment factors are seen as products of unique female motivations and considerations rather than the structure of the labor market itself.

Another explanation for the high levels of job satisfaction among women asserts that women workers are not as concerned with the traditional rewards of high pay and economic mobility because any paid labor represents an improvement over domestic / unpaid labor (Walshok \& Walshok, 1978). These studies assume that women and men bring to the job values and dispositions that are generated primarily by sex-role expectations. Women, accordingly, prefer jobs that produce little conflict with their primary home-care concerns. They prefer jobs with flexibility in respect to home and child-care demands 
and are less concerned about economic rewards, autonomy, and prestige (Gold, 1971).

Sex-role models do not take into account the reward structure of different work environments as a factor influencing job satisfaction or other paid labor correlates (Kanter, 1977; 1982). Research by Bielby and Bielby (1984) demonstrated that labor market and domestic responsibilities explain employment activity itself (full-time work or graduate study) and that these activities are not affected directly by sex-role attitudes.

A fruitful approach to explaining job satisfaction for women workers should incorporate segmented labor market theories that emphasize structural factors. Segmented labor market theories assert that jobs are structured, defined, and rewarded differently for men and women, minority and majority group members, across sectors in the labor force (Bonacich, 1973; Doeringer \& Piore, 1971). That is, opportunities for entry into the labor force, for on-the-job training, for utilization of skills, and for access to full time, steady work, and high economic rewards are not available to men and women at the same rate (Treiman \& Hartmann, 1981).

Particularly significant to the issue of job satisfaction is the finding that women in predominantly female occupations are working in labor markets that structurally produce high turnover rates, greater numbers of part-time positions, and high rates of movement in and out of the wage-labor market (Blau \& Jusenius, 1976). The primary household and child-care responsibilities of women suggest that this secondary market creates a more flexible environment. Experimental research by Christopher Orpen (1981) indicates that clerical workers (all female) show significant increases in job satisfaction when working on flex time. However, Nieva and Gutek (1981) conclude that the workplace for women is not really designed to fit around family responsibilities and that men in managerial and professional occupations have greater structural access to job flexibility and good hours.

In addition, women workers generally are found at lower occupational levels where opportunities for promotion and challenge are limited (Blau, 1977). The structural model suggests that women's satisfaction and rewards may actually be low because "their work structure provides little real opportunity." Women experience structural limitations along with "other groups who do not control the operations of the work organizations" (Nieva \& Gutek, 1981, p. 117). Quinn and Shepard (1973) document that women's paid jobs generally provide fewer social and intrinsic rewards than those held by men. Thus, occupational sectors may provide differing rewards, which may in turn affect job satisfaction (England, 1979; O'Farrell \& Harlan, 1980). The fact that women and men work 
in predominantly sex-segregated spheres of work and that segregation is increasing (U.S. Commission on Civil Rights, 1978) highlights the importance of investigating these structures and their effects.

Andrisani (1978) did draw upon labor market factors to explain job satisfaction outcomes, but he found no significant effects of a market structure. This could well be due to the measurement process: He treated job segmentation (percentage female in an occupation) as a continuous variable. This linear model may mask effects. There may be a tipping point in the impact of percentage female for women and/or men workers which that procedure could not detect. The problem of measuring occupational structures for women has been raised repeatedly in this area of research (England, 1979). In the following analysis, job satisfaction determinants are examined at differing levels of sex segmentation for women and men wage workers.

\section{The Model}

By focusing on sex-segmented labor market sectors, we can move away from the one-dimensional notion that men and women bring to their work differing sets of values based on sex roles alone. We identify determinants of job satisfaction across sex-segmented labor markets. The sectors in which women and men work have consequences for the availability and meaning of rewards and satisfaction. Particularly, traditional sex-role expectations may be mediated by labor market sectors in the following patterns:

Women in female-dominated sectors: When women receive the benefits associated with work in this sector (i.e., work flexibility for domestic and child care, socioemotional support from co-workers, etc.) job satisfaction will be high.

Women in male-dominated sectors: When women receive the benefits associated with this sector (i.e., high economic rewards, autonomy, job challenge, etc.) job satisfaction will be high.

Men in female-dominated sectors: Job satisfaction will not be affected by availability of benefits from this sector as they are not congruent with the "masculine" work roles defined by Gold, etc. Job satisfaction will continue to be affected by income and status factors. Thus, we predict that males in these sectors would have lower job satisfaction scores than any other group of workers.

Men in male-dominated sectors: When men receive the benefits associated with working in this sector (e.g., autonomy, challenge, use of skills, and income) job satisfaction will be high. 


\section{Data and Methods}

A secondary analysis was conducted of the same data base used in Andrisani's 1978 article, that is, the Quinn, Mangione, and Seashore 1973 Quality of Employment national study. Although more than 10 years old, the data are still useful because of the continuing job segregation and income inequality noted in major studies since that time (see Blau, 1977, Stromberg \& Harkess, 1978). Thus, we expect that these inequities and labor market patterns would have similar effects on the women and men in today's labor market.

Data were obtained through personal interviews with 1,496 full- and part-time employed men and women living in the United States and the District of Columbia (see Quinn \& Shepard, 1973, for a full discussion of sampling techniques and sampling error). Information about the quality of employment, labor issues, job satisfaction, intrinsic job factors and their value, work-related behaviors, job stress, the meaning of work, and job standards were obtained.

\section{Job Satisfaction}

The dependent variable in the model is a simple question concerning job satisfaction: "All in all, how satisfied would you say you are with your job? Are you very satisfied, somewhat satisfied, not too satisfied, or not at all satisfied?" Measurement analysis of the variables within this study indicate that this facet-free general measure of job satisfaction is powerful in distinguishing group characteristics (Seashore \& Taber, 1974).

\section{Independent Variables}

Worker's age, education, income, and sex were recorded by individual respondents. Occupational status was coded in accordance with the Duncan Socioeconomic Status Index (Duncan, 1971). Sex was coded as a dummy variable, with female status assigned a value of 1 , male status a value at 0 . To analyze the impact of labor market segmentation, the percentage of women employed in the respondent's occupation was calculated from 1970 industry reports.

The Quality of Employment Survey provides indicators of worker attitudes and values. The research strategy was to identify relevant attitudinal items and to combine these into a series of independent indices that are theoretically relevant to job satisfaction. Past research identifies two 
dimensions as relevant to job satisfaction: (a) external pressures including need of rewards and conflicting environmental pressures; and (b) intrinsic factors of the work environment, including cognitive as well as emotional factors (Pines \& Kafry, 1981).

Methodologically, the goal was to create a set of scales that covary in a stable manner. Items were evaluated for variance among themselves, as well as for primary relationships between the items and a set of criterion variables including worker's age, sex, education, and occupation.

External pressures on women's paid work roles include the reproductive, child care, and domestic roles assigned to women. It is evident that these factors have had a decreasing impact on whether or not women work in the paid labor force (Lloyd \& Niemi, 1979). However, with the responsibility of child care defaulted to women within our family and economic institutions, it is probable that the pressures of child care, maternity, and domestic labor continue to influence women's attitudes toward their work roles (Nieva \& Gutek, 1981). In the Employment Survey, women employees were asked about the availability of maternity leave and the reemployment rights and benefits of postnatal women. These two variables were coded as dummy variables, with a value of 1 indicating that such benefits were available to the woman worker.

Two other external pressures of importance to workers are perceived income needs and the flexibility of work hours. Workers were questioned whether family income was adequate to cover living costs. This variable was scored on a scale of 1 to 4 , with a higher score indicating greater perceived income problems in meeting living costs. A variable was constructed indicating the number of specific problems with hours cited by the respondent.

A series of intrinsic work factors were identified through cannonical correlation analysis. Each variable was shown to covary significantly with the criterion variables of sex, age, income, occupation, and marital status. The coefficients from this analysis were used to weight those items for scaling. Through this process, six intrinsic work factors were identified:

Freedom: A single item indicating the amount of freedom allowed in completing work assignments. Scores ranged from 1 to 4 , with a high score indicating greater freedom.

Job Involvement: A single item response to the question "How involved do you feel in your job?" Scores ranged from 1 to 4 , higher scores indicating greater involvement.

Support: A summed scale from the following (with factor weights):(1) supervisor gets people to work together (.66); (2) my supervisor is friendly (.61); (3) my supervisor helps me get the job done (.29); (4) the people I work for are friendly (.26). Cronbach's alpha for reliability is .79. 
Challenge: This scale is derived from two items: (a) the creativity required on the job (.78) and (b) the ability to learn new things on the job (.37). Cronbach's alpha for scale reliability is .60 .

Skill: This scale is derived from two indicators: (a) the degree of skill required on the job (.59) and (b) whether the worker has "a lot of say" on the job (.64). Cronbach's alpha for the scale is .49.

Relevance: This scale is summed over the following items: (1) the variety of things to do on the job (.29); (2) use of the skills learned in school (.61); (3) job keeps worker up-to-date about the world (.43). Cronbach's alpha is .58.

\section{Research Findings}

We first examined the thesis that percentage female employed in a particular occupation is an important correlate of job satisfaction. This thesis can be tested in two ways; first, with percentage female as a criterion variable for selecting distinct subsamples of women and men workers; and second, with percentage female as a direct correlate of job satisfaction. Although Andrisani (1978) argued that percentage female is not a direct determinant of job satisfaction, we examined a different metric, using cutoff points as a more powerful indicator of labor market sectors and their correlates.

In Table I we consider evidence for using percentage female in the occupation as a criterion variable for a multistage sample selection. The job satisfaction scores indicate that women and men workers constitute distinct samples with significantly different levels of job satisfaction. Percentage female is related to job satisfaction but not in a direct linear fashion. The highest average job satisfaction scores are among women and

Table I. Job Satisfaction Scores for Women and Men across Labor Market Sectors

\begin{tabular}{|c|c|c|c|c|c|c|}
\hline \multirow{2}{*}{$\begin{array}{l}\text { Percentage female } \\
\text { in occupation }\end{array}$} & \multicolumn{3}{|c|}{ Female respondents } & \multicolumn{3}{|c|}{ Male respondents } \\
\hline & $\bar{X}$ & $S D$ & $\%$ & $\bar{X}$ & $S D$ & $\%$ \\
\hline $0-19$ & 2.58 & .50 & 13.1 & 2.54 & .53 & 73.9 \\
\hline $20-39$ & 2.38 & .56 & 12.6 & 2.40 & .58 & 16.1 \\
\hline $40-59$ & 2.30 & .60 & 7.1 & 2.36 & .57 & 4.5 \\
\hline $60-79$ & $2.56^{\mathrm{a}}$ & .55 & 19.2 & $2.41^{\mathrm{a}}$ & .50 & 3.9 \\
\hline $80-100$ & $2.46^{\mathrm{a}}$ & .63 & 48.0 & $2.33^{\mathrm{a}}$ & .62 & 15.6 \\
\hline Total & 2.47 & .54 & 100.0 & 2.51 & .55 & 100.0 \\
\hline
\end{tabular}

a Significant beyond the .001 level. Job satisfaction $\times$ sex group differences, Scheffe procedure. 
men in predominately male occupations. However, the scores for men in predominately female occupations are not significantly lower than those of women in male-dominated occupations. The Scheffe procedure used to analyze significant difference among average group scores is sufficiently robust to take into account the differences in group size. The strongest contrast in job satisfaction is between female and male workers in predominately female sectors. Men in these jobs have significantly lower job satisfaction scores $(p<.01)$ than women in similar occupations.

In Table II, we examine the perceived rates at which the various external and intrinsic factors exist among workers divided between the two labor market sectors as well as between female and male employees. The one-way analysis of variance takes into account the difference in size between the subsamples and therefore is a conservative estimate of actual differences. The average scores on the external factors indicate that income problems are cited more often by workers in the female-segregated occupations and by women workers in general. This is congruent with other research indicating that workers in these sectors generally receive lower economic returns for their labor. Women workers and those workers in predominantly female jobs cite problems with their hours less often than workers in the predominantly male occupations. No significant differences were found between sectors in the availability of maternity leave and benefits for women. ${ }^{1}$

The intrinsic factors are also significantly related to the job sectors as well as respondent gender. Workers in predominantly male jobs are more likely to report their jobs as providing freedom, involvement, job challenge, and use of their skills. The socioemotional factor of support from co-workers and supervisors is significantly more often reported among workers in predominantly female job sectors. The only factor not related to job sector is relevance of the job. Differences between male and female workers parallel the findings for the sex-segmented job sectors. The zeroorder correlations between these factors and percentage female and job satisfaction measures are presented in Table III.

The significant difference in job satisfaction scores, and the nonlinear relationship of percentage female to job satisfaction, provide sufficient evidence for sampling four distinct worker groups: ${ }^{2}$ (a) women who work in predominately female occupations (60-100\% female); (b) men

\footnotetext{
${ }^{1}$ Although some $75 \%$ of women workers reported maternity benefits available to them through their work, only $30 \%$ reported that maternity leaves of absence were available.

${ }^{2} \mathrm{~A}$ saturated model for the prediction equation yielded significant interaction terms for percentage female combined with a range of the intrinsic and external factors. A copy of the analysis is available from the author upon request but is omitted from this manuscript for space considerations.
} 


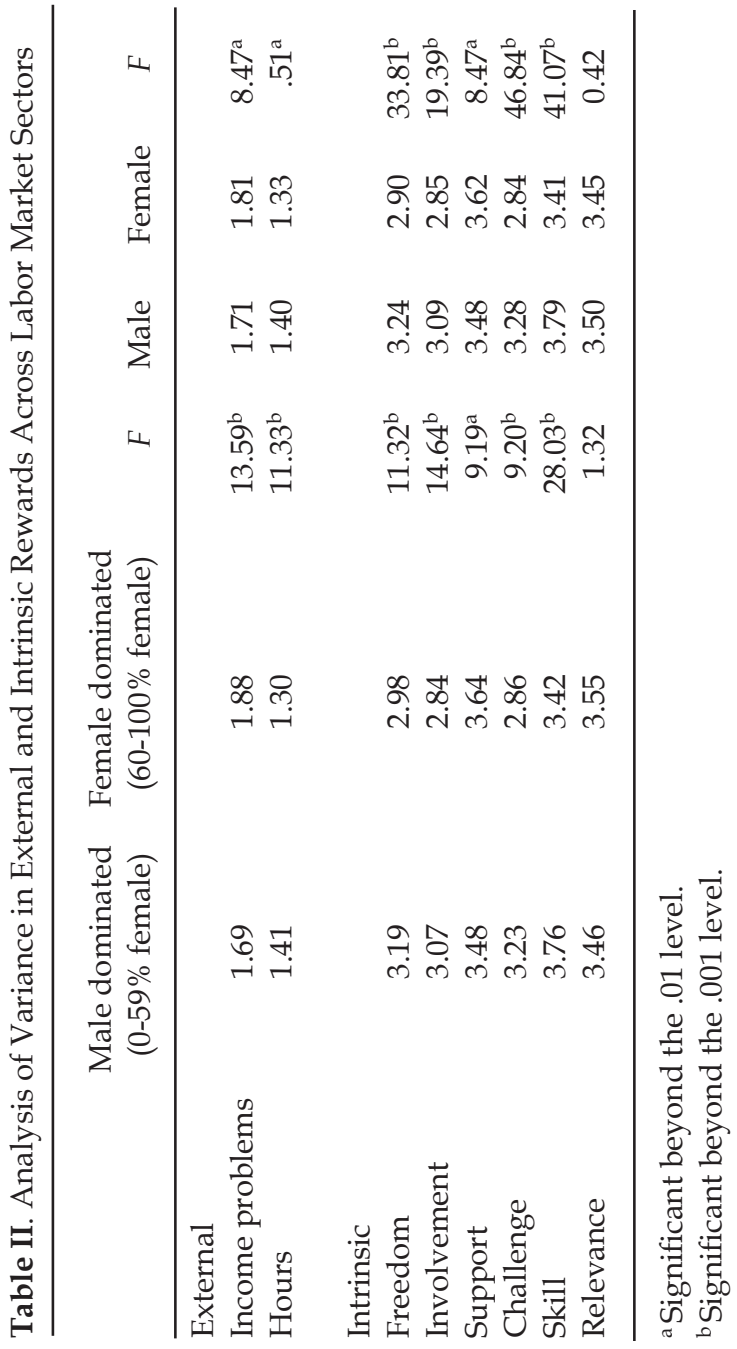


Table III. Zero-Order Correlations for Criterion Variables with Job Satisfaction and Percentage Female

\begin{tabular}{lcc}
\hline \multicolumn{1}{c}{ Variable } & Job satisfaction & \% Female \\
\hline Age & $.237^{c}$ & -.042 \\
Income & $.148^{c}$ & $-.340^{c}$ \\
Occupational status & $.116^{c}$ & $-.069^{\mathrm{b}}$ \\
Degree & $.050^{\mathrm{a}}$ & -.021 \\
Marital status & $-.076^{\mathrm{b}}$ & $.260^{\mathrm{c}}$ \\
Income problems & $-.233^{\mathrm{c}}$ & $.100^{\mathrm{c}}$ \\
Hours & $-.118^{\mathrm{c}}$ & $-.090^{\mathrm{c}}$ \\
Freedom & $.215^{\mathrm{c}}$ & $-.090^{\mathrm{c}}$ \\
Involvement & $.291^{\mathrm{c}}$ & $-.103^{\mathrm{c}}$ \\
Support & $.096^{\mathrm{c}}$ & $.084^{\mathrm{c}}$ \\
Challenge & $.256^{\mathrm{c}}$ & $-.145^{\mathrm{c}}$ \\
Skill & $.355^{\mathrm{c}}$ & $-.142^{\mathrm{c}}$ \\
Relevance & .311 & -.031 \\
\hline
\end{tabular}

a Significant beyond the .05 level; ${ }^{\mathrm{b}}$ Significant beyond the .01 level; ${ }^{\mathrm{c}}$ Significant beyond the .001 level.

who work in predominately female occupations; (c) women who work in predominately male sex-proportionate occupations (0-59\% female), and (d) men who work in predominately these occupations. The disproportionately male and sex-proportionate jobs were combined because of the similarity in job satisfaction scores indicated in Table I.

\section{Job Satisfaction for Men}

We first examine determinants of job satisfaction scores for men who work in predominately male occupations (including occupations that have relatively balanced proportions of male and female workers). This group is the most numerous category of paid workers in our sample, with 724 respondents with complete information. The findings in Table IV indicate that age and occupational status significantly predict job satisfaction for these men. Older respondents report greater job satisfaction. An inverse relationship exists for occupational status, with higher statuses predicting somewhat lower job satisfaction when other demographic and work-related variables are controlled. However, it should be noted that the occupational range is somewhat truncated for these men because generally lower status occupations (predominately held by women and minority workers) are disproportionately excluded.

For men in this labor market sector, the range of work-related factors, both extrinsic and internal, provide significant information for the predic- 
Table IV. Determinants of Job Satisfaction for Women and Men in Predominately Male and Sex-Proportionate Occupations (0-59\% Female)

\begin{tabular}{lcccc}
\hline & \multicolumn{2}{c}{ Women $(n=112)$} & \multicolumn{2}{c}{ Men $(n=724)$} \\
Variable & $b$ & Beta & $b$ & Beta \\
\hline Age & .011 & $.270^{c}$ & .005 & $.111^{\mathrm{c}}$ \\
Income & -.001 & -.062 & -.000 & -.003 \\
Occupation & -.042 & $-.162^{\mathrm{a}}$ & -.017 & $-.070^{\mathrm{b}}$ \\
Education & .043 & .064 & -.018 & -.036 \\
Marital status & -.066 & -.059 & -.043 & -.028 \\
Job tenure & -.040 & -.126 & .009 & .031 \\
Income problems & -.159 & $-.257^{\mathrm{c}}$ & -.133 & $-.188^{\mathrm{c}}$ \\
Hours & -.271 & $-.241^{\mathrm{c}}$ & -.078 & $-.070^{\mathrm{c}}$ \\
Maternity & .021 & .042 & - & - \\
Maternity leave & .077 & .120 & - & - \\
Freedom & .026 & .050 & .036 & $.062^{\mathrm{c}}$ \\
Involvement & .042 & .077 & .104 & $.177^{\mathrm{c}}$ \\
Support & .055 & .077 & .026 & .041 \\
Challenge & .078 & .162 & -.004 & -.007 \\
Skill & .101 & $.189^{\mathrm{c}}$ & .089 & $.167^{\mathrm{c}}$ \\
Relevance & -.058 & -.125 & -.069 & $-.142^{\mathrm{c}}$ \\
$R^{2}$ & .430 & & .254 & \\
Constant & 1.96 & & 1.69 & \\
\hline
\end{tabular}

a Significant beyond the .05 level; ${ }^{b}$ Significant beyond the .01 level; ${ }^{c}$ Significant beyond the .001 level.

tion of job satisfaction. The total variance explained by the model is significant $\left(R^{2}=.254\right)$. As expected, perceived income problems and problems with work hours contribute to lowered job satisfaction scores. Higher levels of freedom, involvement, relevance, and skill predict higher job satisfaction levels for this subsample of workers.

When we consider the prediction equation for male workers in predominately female jobs, the contrasts are striking. First, this subsample is considerably smaller, with only 94 respondents with complete information. Thus, we examine the $b$ coefficients for a comparison to other workers of the magnitude of effects. The total variance explained by the predictor variables is equal to that of other male workers $\left(R^{2}=.264\right)$ but the $y$ intercepts are significantly different. For males in predominately female occupations, the $y$-intercept is 1.28 , whereas the intercept is 1.69 for males in other occupations. This reaffirms the earlier finding of significantly lower job satisfaction scores for men in this predominately female work sector. The $y$-intercepts also identify higher job satisfaction scores for women workers in both subsamples when all factors are controlled.

A different set of factors contribute to the prediction equation for men in female-dominated occupations. The size of the $b$ coefficients for both 
Table V. Determinants of Job Satisfaction for Women and Men in Predominately Female Occupations (60\% or more female)

\begin{tabular}{lcccc}
\hline & \multicolumn{2}{c}{ Women $(n=318)$} & Men $(n=99)$ \\
Variable & $b$ & Beta & $b$ & Beta \\
\hline Age & .006 & $.182^{\mathrm{c}}$ & .005 & .129 \\
Income & .000 & .022 & .001 & .064 \\
Occupation & -.011 & -.050 & -.018 & -.070 \\
Education & -.034 & -.062 & .006 & .014 \\
Marital status & -.014 & -.012 & .038 & .030 \\
Job tenure & .003 & .010 & -.032 & -.107 \\
Income problems & -.089 & $-.141^{\mathrm{c}}$ & -.091 & $-.143^{\mathrm{b}}$ \\
Hours & -.080 & $-.071^{\mathrm{a}}$ & -.080 & -.074 \\
Maternity & -.031 & -.076 & - & - \\
Maternity leave & .050 & $.097^{\mathrm{b}}$ & - & - \\
Freedom & .068 & $.131^{\mathrm{b}}$ & -.014 & -.021 \\
Involvement & .048 & $.082^{\mathrm{b}}$ & .001 & .003 \\
Support & .087 & $.124^{\mathrm{c}}$ & .137 & $.203^{\mathrm{c}}$ \\
Challenge & -.029 & -.060 & -.007 & -.014 \\
Skills & .111 & $.198^{\mathrm{c}}$ & .185 & $.334^{\mathrm{b}}$ \\
Relevance & -.080 & $-.171^{\mathrm{c}}$ & -.098 & $-.206^{\mathrm{b}}$ \\
$\mathrm{R}^{2}$ & .262 & $*$ & & \\
Constant & 1.42 & & .264 & \\
\hline
\end{tabular}

a Significant beyond the .05 level; ${ }^{b}$ Significant beyond the .01 level; ${ }^{c}$ Significant beyond the .001 level.

sets of male workers are relatively similar for the demographic variables. Perceived income problems and flexibility of hours are also similar in magnitude and direction. The internal work factors of support, skill, and relevance make substantial contributions to increased job satisfaction for men in these predominately female sectors. The $b$ coefficient for support is several times larger than that in the equation for men in predominately male or sex proportionate sectors.

\section{Job Satisfaction for Women}

Job satisfaction scores for women workers do not vary significantly with job segregation, and the $y$-intercepts in both equations for the male subsamples indicate greater job satisfaction for women workers when other factors are controlled. However, we hypothesized that the factors affecting job satisfaction might vary between the sex-segregated groups of workers. For women who work in predominately male or sex-propor- 
tionate occupations, the significant factors for predicting job satisfaction are age, occupational status, and reported problems with family income and hours. The skill variable is the only intrinsic factor to have a statistically significant beta.

Two interesting profiles emerge. First, the most salient factors for job satisfaction among these women workers are income issues and flexibility of hours which closely parallel the factors for men in the same job sector. Second, the issues of maternity benefits and maternity leave do not contribute significantly to job satisfaction.

The explained variance in job satisfaction scores $\left(R^{2}=.430\right)$ is the highest of any subsample of workers. These women work in a variety of careers, ranging from lawyers, doctors, and construction workers to barbers. The occupational status variable, with its great range, has independent effects beyond perceived income factors alone.

Women in the predominately female job sector occupy job statuses ranging from nurse and noncollege teacher to seamstress, factory assembler, and private household worker. These occupations range widely in prestige and educational prerequisites, but the income ranges for women in these fields are truncated and significantly lower than those of women in the other sector. We hypothesized that factors for women in predominately female sectors will differ substantially.

Women in predominately female occupations constitute over twothirds of our total sample of women respondents. Table $\mathrm{V}$ indicates that these women are tied to job satisfaction by a distinct cluster of factors. Of the demographic variables, only age is a significant predictor, with higher age indicating greater satisfaction with the job.

The added external pressures and intrinsic work factors provide significant information about job satisfaction. Perceived income problems, rather than actual incomes, are related to lower job satisfaction. Flexibility of hours and the availability of maternity leave are significant contributors to greater satisfaction. A comparison of $b$ coefficients suggest that these maternity leave and benefit variables have similar magnitude of effects for women workers in both sectors of the labor market.

Almost all of the intrinsic job factors enter the prediction equation for women in female-dominated job sectors. This pattern is significant in detailing the complexity of the paid women worker's response to her environment. Freedom within the work environment, involvement with the job, the use of acquired skills, and the relevance of the job are integral to job satisfaction, as well as those socioemotional indicators emphasized in past research. For both sets of women workers, the $b$ coefficients indicate a similar magnitude of effects for these intrinsic factors, with the exception of freedom on the job and job challenge. 


\section{Discussion}

By investigating subsamples of workers who are segmented by sex into distinct labor market sectors, we find variation in the rewards and satisfactions accrued by women and men workers. Women workers in general have higher job satisfaction scores, once other market factors are controlled. However, we demonstrated that the context of their work (in this case sex segmentation of occupations and rewards) is both substantively different and organizes factors related to job satisfaction. Generally, both women and men in male-dominated or sex-proportionate sectors perceive their jobs as providing greater income, freedom, job involvement, job challenge, and use of their skills. These benefits are in addition to the significantly higher income for these jobs. The only benefit accruing disproportionately to the female-dominated sector is perceived support of supervisors and co-workers.

Consistently, the job satisfaction of all workers, both men and women in all sectors of the labor market, is predicted by both perceived income problems and the flexibility of hours cited. These factors are most salient for women in predominately male or sex-proportionate occupations. The perception of income problems outweighs actual income as a factor of job satisfaction in both the zero-order correlations and the regression analyses.

For women who are employed in predominately female sectors, job satisfaction is affected by a wide range of intrinsic challenges, socioemotional factors, and perceived income issues, as well as the flexibility of hours and availability of benefits tied to domestic responsibilities. For women in predominately male occupations, support of co-workers is not salient. Economic factors (perceived income problems), use of skills, and flexibility of hours are the primary factors affecting job satisfaction. We reemphasize that benefits associated with the reproductive roles of women are not differentially available across the two sectors but are unavailable to women workers in general and have relatively similar magnitude of effects on job satisfaction.

These relationships contradict the argument by Walshok and Walshok (1978) that, for women workers in general, job satisfaction is high because any income is better than no income. We cannot presume to account for the high job satisfaction of these workers by a sex-role model of low income expectations. The labor market models suggest that women in female-dominated occupations do respond somewhat to trade-offs that accompany secondary labor markets: for example, the ability to organize paid labor around the demands of the family and support of co-workers. However, women who work in predominately male or sex-proportionate 
sectors of the labor market are no more or less influenced in their job satisfaction by these intrinsic factors.

For men in predominately female occupations, job satisfaction is significantly lower and satisfaction is closely tied to the intrinsic support factors. Perceived income problems, flexibility of hours, and use of skills are the remaining predictors. The contrasts between the two subsamples of male workers are primarily in the ${ }^{\wedge}$-intercepts and the set of intrinsic work factors that affect job satisfaction levels. Clearly, the work environment for men in predominately female occupations has a significant effect in lowering job satisfaction scores.

Interestingly, the cohort of men in male-dominated or sex-proportionate occupations has patterns similar to women working in traditional, female-segmented sectors of the labor market. The full array of job satisfaction predictors, including intrinsic job factors and external pressures, are salient for those workers who participate in a job sector that comprises predominately workers of the same sex. This network of variables, then, accounts for a significant proportion of job satisfaction among men traditionally defined as seeking challenging and instrumental types of work. These same factors are taken into account by the women who work in the pink-collar sectors of the labor market, including the semiprofessions, service, and clerical jobs. Clearly, women in these jobs derive similar intrinsic rewards in order to rate themselves as satisfied with their work, even though freedom, job involvement, and the use of skills are reported as less available to them.

The overall conclusion from this research is that linear indices of job environments are weak descriptors of the true segmented structure of the labor market and attitudes related to work. Job sectors are clearly related to the availability of rewards and the work conditions that determine job satisfaction. These sectors significantly mediate sex-role factors in predicting job satisfaction. Women and men base their job satisfaction upon the frameworks of benefits and rewards associated with the sectors of the labor market in which they are employed, as opposed to the traditional sex-role values that they may bring to their jobs.

\section{References}

Andrisani, P. J. Job satisfaction among working women. Signs: Journal of Women in Culture and Society, 1978, 3, 588-607.

Bielby, D. D., \& Bielby, W. Work commitment and sex-role attitudes. American Sociological Review, 1984, 49, 234-247.

Blau, F. Equal pay in the office. Lexington, MA: D. C. Heath, 1977. 
Blau, F., \& Jusenius, C. L. Economists' approaches to sex segregation of the labor market: An appraisal. In: Blaxall \& Reagan (Eds.), Women and the workplace. Chicago: University of Chicago Press, 1976.

Bonacich, E. J. A theory of ethnic antagonism: Split labor market theory. American Sociological Review, 1973, 37, 547-559.

Doeringer, P., \& Piore, M. Internal labor markets and manpower analysis. Lexington, MA:Lexington Books, 1971.

Duncan, O. D. A socioeconomic index for all occupations. In A. J. Reiss (Ed.), Occupations and social status. New York: Free Press, 1971.

England, P. Women and occupational prestige: A case of vacuous sex equality. Signs: Journal of Women in Culture and Society, 1979, 5, 252-265.

Feldberg, R. L., \& Glenn, E. N. Male and female: Job versus gender models in the sociology of work. In R. Kahn-Hut, A. K. Daniels, \& E. Clovard (Eds.), Women and work. New York: Oxford University Press, 1982.

Gold, D. B. Women and voluntarism. In Gornick \& Moran (Eds.), Woman in sexist society. New York: Mentor Books, 1971.

Kanter, R. M. Men and women of the corporation. New York: Basic Books, 1977.

Kanter, R. M. The impact of hierarchical structures on work behavior of women and men. In R. Kahn-Hut, A. K. Daniels, \& E. Clovards (Eds.), Women and work. Cambridge: Oxford University Press, 1982.

Lloyd, C. B., \& Niemi, B. T. The economics of sex differentials. New York: Columbia University Press, 1979.

Nieva, V., \& Gutek, B. Women and work: A psychological perspective. New York: Praeger, 1981.

O'Farrell, B., \& Harlan, S. Craftworkers and clerks: The effect of male co-worker hostility on women's satisfaction with non-traditional jobs. Working paper: Wellesley, MA: Center for Research on Women, Wellesley College, 1980.

O'Leary, V. Some attitudinal barriers to occupational aspirations in women. Psychological Bulletin, 1981, 8, 809-826.

Orpen, C. Effect of flexible working hours on employee satisfaction and performance: A field experiment. Journal of Applied Psychology, 1981, 6, 113-116.

Pines, A., \& Kafry, D. Tedium in the life and work of professional women as compared with men. Sex Roles, 1981, 7, 963-977.

Quinn, R., \& Shepard, L. The 1972-73 Quality of Employment Survey. Ann Arbor, MI: Survey Research Center of the Institute for Social Research, 1973.

Seashore, S., \& Taber, T. Job satisfaction indicators and their correlates. Paper presented at the Conferences on the Quality of Employment Indicators, Silver Springs, MD, 1974.

Stromberg, A., \& Harkess, S. Women working. Palo Alto, CA: Mayfield Press, 1978.

Treiman, D., \& Hartman, H. Women, work and wages. Washington, DC: National Academy Press, 1981.

U.S. Commission on Civil Rightts. Social indicators of equality for minorities and women. Washington, DC: U.S. Government Printing Office, 1978.

Walshok, M. G., \& Walshok, M. G. The personal and social benefits of paid employment for urban women in skilled and semiskilled occupations. Paper presented at the Ninth World Congress of Sociology, Uppsala, Sweden, 1980. 